\title{
Saprolegnia species in Norwegian salmon hatcheries: field survey identifies $S$. diclina sub-clade IIIB as the dominating taxon
}

\author{
E. Thoen ${ }^{1}$, T. Vrålstad ${ }^{1}$, E. Rolén ${ }^{1}$, R. Kristensen ${ }^{1}$, Ø. Evensen ${ }^{2}$, I. Skaar ${ }^{1, *}$ \\ ${ }^{1}$ Norwegian Veterinary Institute, PO Box 750 Sentrum, 0106 Oslo, Norway \\ ${ }^{2}$ Norwegian University of Life Sciences, PO Box 8146 Dep., 0033 Oslo, Norway
}

\begin{abstract}
Saprolegnia isolates within the recognized clades encompassing the taxa $S$. parasit$i c a$ and $S$. diclina act as opportunist and aggressive pathogens to both fish and their eggs. They are responsible for significant economic losses in aquaculture, particularly in salmonid hatcheries. However, the identity, distribution and pathogenic significance of involved species often remain unexplored. In this study, 89 Saprolegnia isolates were recovered from water, eggs and salmon tissue samples that originated from salmon (Salmo salar) hatcheries along the coast of Norway. The cultures were characterized morphologically and molecularly in order to provide an overview of the species composition of Saprolegnia spp. present in Norwegian salmon hatcheries. We demonstrate that $S$. diclina clearly dominated and contributed to $79 \%$ of the recovered isolates. Parsimony analyses of the nuclear ribosomal internal transcribed spacer (ITS) region split these isolates into 2 strongly supported sub-clades, $S$. diclina sub-clade IIIA and IIIB, where sub-clade IIIB accounted for $66 \%$ of all isolates. A minor portion of the isolates constituted other taxa that were either conspecific or showed strong affinity to $S$. parasitica, S. ferax, S. hypogyna and Scoliolegnia asterophora. The unique sub-clade IIIB of $S$. diclina was most prevalent in water and salmon eggs, while $S$. parasitica isolates were more frequently isolated from post hatching stages. The study demonstrated that morphological criteria in many cases were insufficient for species delimitation due to lack of sexual structures or incoherent morphological expression of such features within the tested replicates.
\end{abstract}

KEY WORDS: Aquaculture $\cdot$ Salmo salar $\cdot$ Pathogen $\cdot$ Eggs $\cdot$ Oomycetes

\section{INTRODUCTION}

Saprolegnia infections are economically burdensome fish diseases occurring mainly throughout the freshwater phase in salmonid aquaculture, but also in wild fish. The causative organisms, species within the oomycete genus Saprolegnia, have been subject to research since they were first described by Arderon in 1748 (Hughes 1994). Scientific approaches span from the exploration of new species and pathogen-host relationships (Diéguez-Uribeondo et al.

\footnotetext{
*Corresponding author: ida.skaar@vetinst.no
}

2007 ) to the full genome sequencing of $S$. parasitica (van West 2006).

The occurrence of oomycetes in salmonid hatcheries has been investigated in Japan and Spain, but only to a rather limited extent given the nature of the problem (Kitancharoen et al. 1997, Hussein et al. 2001, Fregeneda-Grandes et al. 2007). These studies characterized the Saprolegnia species sampled from incubating eggs and fry. However, reports on the diversity of Saprolegnia within hatchery water systems are scarce (Olàh \& Farkas 1978). As a conse-

(C) The authors 2015. Open Access under Creative Commons by Attribution Licence. Use, distribution and reproduction are unrestricted. Authors and original publication must be credited. 
quence, very little is known about the sapro-ecological aspects within water systems of commercial aquaculture facilities and their implications with regard to infection pressure in the different life stages of the fish. It is becoming increasingly clear that the allencompassing term saprolegniosis is not a single disease, but rather a conglomerate of disease conditions occurring at different life stages, with aetiologies involving different causative species and an array of external factors. Examples of the latter are stress, prior disease and environmental conditions. Knowledge about the pathogen and its ecology within the ecosystem in an aquaculture facility is of importance in order to develop control measures. Even though Norway is a leading country in salmonid aquaculture, very little is known about the occurrence of oomycetes in salmon hatcheries, with regard to both species and quantities. In the present study, we therefore aimed to perform the first extensive survey of the Saprolegnia species in Norwegian salmon hatcheries. Saprolegnia isolates collected from water systems of 26 salmon hatcheries along the coast of Norway were characterized morphologically, physiologically and molecularly. In addition, Saprolegnia spp. from infected eggs and fish were isolated from those hatcheries where such samples were available, to compare with isolates found in water.

\section{MATERIALS AND METHODS}

\section{Hatcheries}

The 26 hatcheries supplying samples were all commercially run operations with production capacities

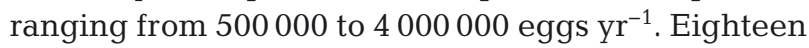
hatcheries were independent operations selling smolts to other companies, while 8 were an integrated part of a company production chain. None of the hatcheries employed recirculating aquaculture systems, and their water supply came from rivers, lakes, ground water or combinations of these. Moreover, the hatching systems that were employed varied; flow-through hatching trays were most common (16 hatcheries), while hatching cabinets (Comphatch ${ }^{\circledR}$, Alvestad marin AS) and hatching tanks (Maxiklekk, Namdalsplast AS) were used in 12 and 5 hatcheries, respectively. Salmon eggs (Salmo salar) were supplied by the 2 main salmon breeding companies in Norway. Eggs were iodine disinfected before shipment or upon receipt in the hatcheries. Outbreaks of Saprolegnia infection were not noted in any of the hatcheries during the sampling period.

\section{Isolation of Saprolegnia from hatchery water}

Water samples were collected from effluent water after passing through the hatching units with incubating salmon eggs, from a total of 26 salmon hatcheries located along the coastline of Norway. The sampling sites were spread from the southernmost county Agder to the northernmost county Finnmark (see the inset map in Fig. 1 for an overview). For each water sample, 96-well microwell plates $(n=3)$ were filled with $100 \mu \mathrm{l}$ of water per well. The plates were incubated in darkness at $20^{\circ} \mathrm{C}$ and screened for emerging colonies after 24 and 48 h. Emerging Saprolegnia colonies were identified and sub-cultured according to Thoen et al. (2010). From the microwell plates, 3 to 6 emerging Saprolegnia colonies were chosen randomly for pure culture isolation and further characterization. The selected colonies were transferred aseptically from the microwells by pipetting into Petri dishes containing glucose yeast (GY) broth (Hussein \& Hatai 2002) with added streptomycin/ampicillin $\left(200 \mathrm{mg} \mathrm{l}^{-1}\right)$ for propagation at $20 \pm$ $1^{\circ} \mathrm{C}$ in darkness for 2 to $3 \mathrm{~d}$. To induce zoosporangial formation, a sufficient amount of mycelium was rinsed in filtered, autoclaved aquarium water, cut into smaller tufts and divided into 3 replicate dishes containing the same kind of water. Whole, peeled, autoclaved hemp seeds in Petri dishes with sterile aquarium water were used to culture the isolates for observation of sexual reproduction. The dishes were kept in a refrigerator $\left(5 \pm 1^{\circ} \mathrm{C}\right)$ and in an incubator $\left(15 \pm 1^{\circ} \mathrm{C}\right)$ for 8 and $3 \mathrm{wk}$, respectively, in order to observe development of diagnostic sexual morphological characters. Single spore cultures for longterm storage were produced from zoospores collected from all isolates, and stored at $4^{\circ} \mathrm{C}$ on hemp seeds in sterilized aquarium water (Stueland et al. 2005)

\section{Isolation of Saprolegnia from fish tissues}

Saprolegnia strains were isolated from eggs and tissue samples (e.g. gills) or newly hatched larvae from 10 of the hatcheries by transferring specimens with suspected Saprolegnia infections to a sterile plastic bottle (sodium thiosulphate-buffered, sterile Sterilin ${ }^{\circledR}$ water sampling bottles, $500 \mathrm{ml}$ volume with rubber stopper and aluminium seal) filled with tap water. The samples were sent via overnight express with cooling and were processed upon arrival at the laboratory. The tissue sample, or mycelium excised from it, was transferred to a GY agar plate with 


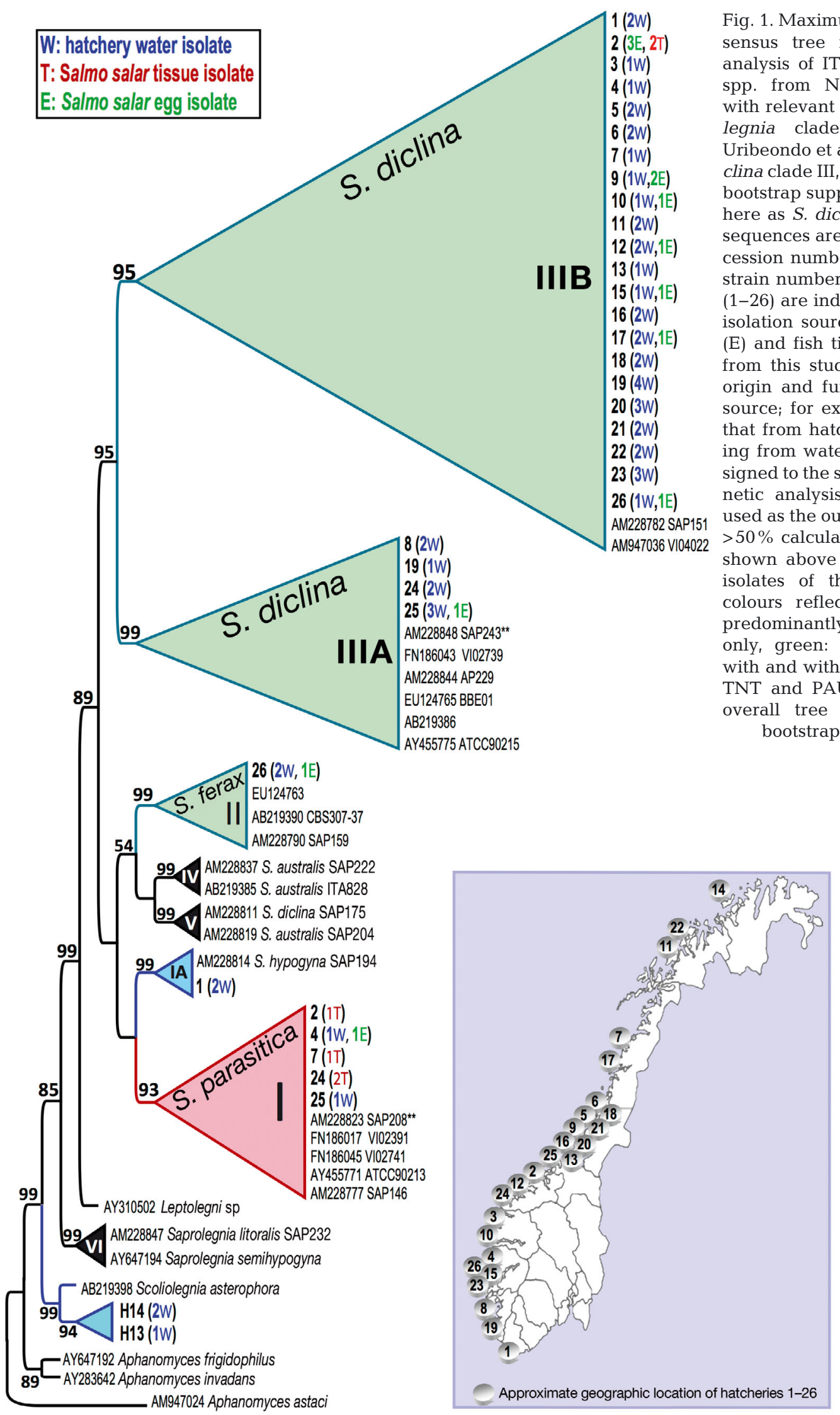


antibiotics within a sterile glass ring serving as a barrier to the growth of yeasts and potential resistant bacteria. Oomycete mycelium growing through the agar was isolated and maintained as described above. If the above described regime was insufficient to de-contaminate the culture, such isolates were propagated in GY broth with chloramphenicol $\left(50 \mathrm{mg} \mathrm{l}^{-1}\right.$ ) in successive cycles until they were free from contaminating bacteria, and then maintained as described above. All isolates included in the present study are listed in Table 1 along with accompanying information on origin, isolation source and isolate reference number.

\section{Morphological characterization}

Morphological characterization was performed according to Seymour (1970) and Willoughby (1985). Each culture was prepared and examined in triplicate. For diagnostic morphological features of sexual reproduction, each feature was observed a minimum of 5 times per replicate (10 observations if possible). Identification of non-sexual $S$. parasitica was based on observation of long hairs on the secondary cysts, degree of indirect germination and source of isolation (Willoughby 1985, Beakes et al. 1994).

Germination rate in sterilized tap water and germination pattern (direct or indirect) were investigated for a majority of the isolates. Germination rate was examined according to Stueland et al. (2005), except that at least 50 cysts were observed in triplicates. The germination pattern was examined as described by Yuasa et al. (1997) after obtaining secondary cysts according to Fregeneda-Grandes et al. (2007). Duplicates of approximately 100 cysts were observed. Isolates of $S$. ferax and $S$. hypogyna were differentiated by observation of hypogynous antheridia produced in the latter. A number of the morphologically characterized isolates were lost during storage or could not generate satisfactory internal transcribed spacer (ITS) sequences. Such isolates were only included when sequenced and morphological identical isolates from the same hatchery were available (Table 1).

\section{Molecular characterization}

In total, 73 single-spore culture isolates of putative $S$. diclina, $S$. parasitica, $S$. ferax, S. hypogyna and Saprolegnia sp. were subjected to molecular analyses in order to compare and test the morpho- logical determination. Genomic DNA was extracted from $\sim 20 \mathrm{mg}$ mycelia from each isolate using a CTAB miniprep extraction protocol (Gardes \& Bruns 1993) according to the modifications described by Vrålstad et al. (2009), with minor adjustments. Briefly, $700 \mu \mathrm{l}$ of CTAB buffer $\left(20 \mathrm{~g} \mathrm{l}^{-1}\right.$ CTAB, $1.4 \mathrm{M} \mathrm{NaCl}, 0.1 \mathrm{M}$ tris-HCl, $20 \mathrm{mM}$ $\mathrm{Na}_{2}$ EDTA) was added to the material in Precellys ${ }^{\circledR}$ MK28 tubes (Bertin Technologies) before grinding, lysation and homogenizing by use of a homogenizer (Precellys ${ }^{\circledR} 24$, Bertin Technologies). The samples were then frozen $\left(-80^{\circ} \mathrm{C}\right.$, minimum $10 \mathrm{~min})$, heated $\left(65^{\circ} \mathrm{C}, 5-10 \mathrm{~min}\right)$ and centrifuged (5 min) before proceeding with the DNA extraction procedure described above. From a few culture isolates, DNA was extracted using NucliSENS ${ }^{\circledR}$ easyMAG $^{\circledR}$ (BioMérieux). Mycelia were added to 700 $\mu l$ NucliSENS easyMAG lysis buffer in Precellys MK28 tubes before grinding and homogenization with Precellys as described above. The samples were then frozen $\left(-80^{\circ} \mathrm{C}\right.$, minimum of $\left.10 \mathrm{~min}\right)$, heated $\left(65^{\circ} \mathrm{C}, 5-10 \mathrm{~min}\right)$ and centrifuged (5 min). The supernatants (approximately $650 \mu \mathrm{l}$ ) were transferred to the sample vessels and an additional $350 \mu \mathrm{l}$ of NucliSENS easyMAG lysis buffer were added to the samples to a total volume of $1 \mathrm{ml}$. Genomic DNA was then isolated by use of NucliSENS easyMAG following the manufacturer's instructions.

The ITS-region was amplified using the universal primers ITS1 and ITS4 (White et al. 1990). The $25 \mu \mathrm{l}$ reaction consisted of $1.7 \mu \mathrm{M}$ of each primer, $2 \mu \mathrm{l}$ of genomic DNA, PuReTaq Ready-To-Go ${ }^{\mathrm{TM}}$ PCR Beads (Amersham Biosciences) and milliQ water. PCR was performed on a DNA Engine Tetrad ${ }^{\circledR}$ Peltier Thermal Cycler (PTC-225, MJ Research) using initial denaturation $\left(95^{\circ} \mathrm{C}, 10 \mathrm{~min}\right), 38$ cycles of amplification $\left(95^{\circ} \mathrm{C}\right.$ for $1 \mathrm{~min}, 55^{\circ} \mathrm{C}$ for $45 \mathrm{~s}, 72^{\circ} \mathrm{C}$ for $\left.1 \mathrm{~min}\right)$ and a final elongation $\left(72^{\circ} \mathrm{C}\right.$ for $\left.5 \mathrm{~min}\right)$. The PCR amplicons were visualized by gel electrophoresis on a $1.5 \%$ agarose gel stained with ethidium bromide, using pUC Mix Marker, 8, ready-to-use (19-1118 bp; Fermentas) for sizing of DNA fragments. PCR products were purified with ExoSAP-IT (Amersham Biosciences) according to the manufacturer's protocol. The products were then sequenced in both directions with their respective primers, using the The BigDye ${ }^{\circledR}$ Terminator v3.1 Ready Reaction mix (Applied Biosystems, Life Technologies). The sequencing PCR program consisted of initial denaturation $\left(96^{\circ} \mathrm{C}\right.$ for $1 \mathrm{~min}$ ) and $40 \mathrm{cycles}$ of $96^{\circ} \mathrm{C}$ for $10 \mathrm{~s}, 56^{\circ} \mathrm{C}$ for $5 \mathrm{~s}$ and $60^{\circ} \mathrm{C}$ for $4 \mathrm{~min}$. The sequencing PCR products were purified with a BigDye ${ }^{\circledR}$ XTerminator Purification Kit 
Table 1. Overview of the origin, source and characteristics of the 89 isolates obtained. Origin: region (county) in Norway (North: Finmark, Troms, Nordland; Central: N. Trøndelag, S. Trøndelag; West: Møre og Romsdal, Sogn og Fjordane, Hordaland, Rogaland; South: Agder). VI numbers refer to the isolate ID number in the culture collection of the Norwegian Veterinary Institute. Presence or absence of sexual structures (oogonia and antheridia) is indicated. SGR: spore germination rate (\%) in sterile tap water. Morphological and phylogenetic ID indicate identification based on morphological/physiological characters and phylogenetic analyses of ITS-sequences, respectively. The phylogenetic identification is based on ITS-sequence accession numbers from public sequence databases (EMBL/GenBank/DDBJ). Asterisks indicate that morphological characters were identical to sequenced isolates from the same hatchery. ND: not determined; NA: not available; s-c: sub-clade

\begin{tabular}{|c|c|c|c|c|c|c|c|c|}
\hline $\begin{array}{l}\text { Hatchery } \\
\text { ID }\end{array}$ & Origin & Culture ID & Source & Sexual & $\begin{array}{l}\text { Long cyst } \\
\text { hairs }\end{array}$ & SGR & $\begin{array}{c}\text { Morphological } \\
\text { ID }\end{array}$ & $\begin{array}{l}\text { Phylogenetic } \\
\text { ID }\end{array}$ \\
\hline \multirow[t]{4}{*}{1} & Agder & VI 05423 & Water & Yes & No & 5 & S. hypogyna & S. hypogyna \\
\hline & Agder & VI 05424 & Water & Yes & No & 4 & S. hypogyna & S. hypogyna \\
\hline & Agder & VI 03804 & Water & Yes & No & 0 & S. diclina & S. diclina s-c IIIB \\
\hline & Agder & VI 03805 & Water & Yes & No & 0 & S. diclina & S. diclina s-c IIIB \\
\hline \multirow[t]{6}{*}{2} & S. Trøndelag & VI 03788 & Eggs & Yes & No & 0 & S. diclina & S. diclina s-c IIIB \\
\hline & S. Trøndelag & VI 03779 & Eggs & Yes & No & 2 & S. diclina & S. diclina s-c IIIB \\
\hline & S. Trøndelag & VI 03797 & Eggs & Yes & No & 2 & S. diclina & S. diclina s-c IIIB \\
\hline & S. Trøndelag & VI 03800 & Gill, broodst. & No & Yes & 39 & S. parasitica & S. parasitica \\
\hline & S. Trøndelag & VI 03796 & Gill, broodst. & Yes & No & 12 & S. diclina & S. diclina s-c IIIB \\
\hline & S. Trøndelag & VI 03780 & Gill, broodst. & Yes & No & 6 & S. diclina & S. diclina s-c IIIB \\
\hline \multirow[t]{4}{*}{3} & Sogn og Fjordane & VI 03794 & Water & Yes & No & 1 & S. diclina & S. diclina s-c IIIB \\
\hline & Sogn og Fjordane & VI 05287 & Water & Yes & No & 0 & S. diclina* ${ }^{*}$ & NA \\
\hline & Sogn og Fjordane & VI 05288 & Water & Yes & No & 0 & S. diclina* ${ }^{*}$ & NA \\
\hline & Sogn og Fjordane & VI 05289 & Water & Yes & No & ND & S. diclina* & NA \\
\hline \multirow[t]{4}{*}{4} & Hordaland & VI 03787 & Eggs & No & Yes & 42 & S. parasitica & S. parasitica \\
\hline & Hordaland & VI 03777 & Water & No & Yes & 39 & S. parasitica & S. parasitica \\
\hline & Hordaland & VI 03781 & Water & Yes & No & 0 & S. diclina & S. diclina s-c IIIB \\
\hline & Hordaland & VI 05446 & Water & Yes & No & 2 & S. diclina* & NA \\
\hline \multirow[t]{3}{*}{5} & N. Trøndelag & VI 03782 & Water & Yes & No & 0 & S. diclina & S. diclina s-c IIIB \\
\hline & N. Trøndelag & VI 03792 & Water & Yes & No & 2 & S. diclina & S. diclina s-c IIIB \\
\hline & N. Trøndelag & VI 05290 & Water & Yes & No & 0 & S. diclina* & NA \\
\hline \multirow[t]{2}{*}{6} & N. Trøndelag & VI 03783 & Water & Yes & No & 0 & S. diclina & S. diclina s-c IIIB \\
\hline & N. Trøndelag & VI 03784 & Water & Yes & No & 3 & S. diclina & S. diclina s-c IIIB \\
\hline \multirow[t]{4}{*}{7} & Nordland & VI 03809 & Water & Yes & No & 0 & S. diclina & S. diclina s-c IIIB \\
\hline & Nordland & VI 03810 & Fry & No & Yes & 56 & S. parasitica & S. parasitica \\
\hline & Nordland & VI 05284 & Eggs & No & Yes & 42 & S. parasitica* ${ }^{*}$ & NA \\
\hline & Nordland & VI 05285 & Fry & No & Yes & 59 & S. parasitica* ${ }^{*}$ & NA \\
\hline \multirow[t]{4}{*}{8} & Rogaland & VI 03776 & Water & Yes & No & 0 & S. diclina & S. diclina s-c IIIA \\
\hline & Rogaland & VI 03778 & Water & Yes & No & 0 & S. diclina & S. diclina s-c IIIA \\
\hline & Rogaland & VI 05292 & Water & Yes & No & 0 & S. diclina* $^{*}$ & NA \\
\hline & Rogaland & VI 05293 & Water & Yes & No & 4 & S. diclina* & NA \\
\hline \multirow[t]{3}{*}{9} & S. Trøndelag & VI 03807 & Eggs & Yes & No & 3 & S. diclina & S. diclina s-c IIIB \\
\hline & S. Trøndelag & VI 03806 & Eggs & Yes & No & 0 & S. diclina & S. diclina s-c IIIB \\
\hline & S. Trøndelag & VI 03811 & Water & Yes & No & 0 & S. diclina & S. diclina s-c IIIB \\
\hline \multirow[t]{2}{*}{10} & Sogn og Fjordane & VI 03808 & Water & Yes & No & 0 & S. diclina & S. diclina s-c IIIB \\
\hline & Sogn og Fjordane & VI 03790 & Eggs & Yes & No & 0 & S. diclina & S. diclina s-c IIIB \\
\hline \multirow[t]{3}{*}{11} & Troms & VI 03799 & Water & Yes & No & 0 & S. diclina & S. diclina s-c IIIB \\
\hline & Troms & VI 03791 & Water & Yes & No & 2 & S. diclina & S. diclina s-c IIIB \\
\hline & Troms & VI 05294 & Water & Yes & No & 1 & S. diclina* & NA \\
\hline \multirow[t]{4}{*}{12} & Møre og Romsdal & VI 03812 & Water & Yes & No & 0 & S. diclina & S. diclina s-c IIIB \\
\hline & Møre og Romsdal & VI 05296 & Water & Yes & No & 0 & S. diclina* & NA \\
\hline & Møre og Romsdal & VI 03820 & Water & Yes & No & 1 & S. diclina & S. diclina s-c IIIB \\
\hline & Møre og Romsdal & VI 03813 & Eggs & Yes & No & 1 & S. diclina & S. diclina s-c IIIB \\
\hline \multirow[t]{3}{*}{13} & S. Trøndelag & VI 05447 & Water & Yes & No & 0 & S. diclina* & NA \\
\hline & S. Trøndelag & VI 03814 & Water & Yes & No & 2 & Saprolegnia sp. & Scoliolegnia sp. \\
\hline & S. Trøndelag & VI 03815 & Water & Yes & No & 0 & S. diclina & S. diclina s-c IIIB \\
\hline \multirow[t]{3}{*}{14} & Finmark & VI 03785 & Water & Yes & No & 0 & Saprolegnia sp. & Scoliolegnia sp. \\
\hline & Finmark & VI 03793 & Water & Yes & No & 0 & Saprolegnia sp. & Scoliolegnia sp. \\
\hline & Finmark & VI 05286 & Water & Yes & No & 2 & Saprolegnia sp. & NA \\
\hline
\end{tabular}


Table 1 (continued)

\begin{tabular}{|c|c|c|c|c|c|c|c|c|}
\hline $\begin{array}{l}\text { Hatchery } \\
\text { ID }\end{array}$ & Origin & Culture ID & Source & Sexual & $\begin{array}{l}\text { Long cyst } \\
\text { hairs }\end{array}$ & SGR & $\begin{array}{l}\text { Morphological } \\
\text { ID }\end{array}$ & $\begin{array}{c}\text { Phylogenetic } \\
\text { ID }\end{array}$ \\
\hline \multirow[t]{2}{*}{15} & Hordaland & VI 03816 & Water & Yes & No & 4 & S. diclina & S. diclina s-c IIIB \\
\hline & Hordaland & VI 03817 & Eggs & Yes & No & 3 & S. diclina & S. diclina s-c IIIB \\
\hline \multirow[t]{2}{*}{16} & N. Trøndelag & VI 03818 & Water & Yes & No & 0 & S. diclina & S. diclina s-c IIIB \\
\hline & N. Trøndelag & VI 03819 & Water & Yes & No & 0 & S. diclina & S. diclina s-c IIIB \\
\hline \multirow[t]{3}{*}{17} & Nordland & VI 03774 & Eggs & Yes & No & 3 & S. diclina & S. diclina s-c IIIB \\
\hline & Nordland & VI 03775 & Water & Yes & No & 0 & S. diclina & S. diclina s-c IIIB \\
\hline & Nordland & VI 03798 & Water & Yes & No & 0 & S. diclina & S. diclina s-c IIIB \\
\hline \multirow[t]{2}{*}{18} & N. Trøndelag & VI 03801 & Water & Yes & No & 0 & S. diclina & S. diclina s-c IIIB \\
\hline & N. Trøndelag & VI 03795 & Water & Yes & No & 0 & S. diclina & S. diclina s-c IIIB \\
\hline \multirow[t]{4}{*}{19} & Rogaland & VI 03786 & Water & Yes & No & 3 & S. diclina & S. diclina s-c IIIB \\
\hline & Rogaland & VI 03789 & Water & Yes & No & 3 & S. diclina & S. diclina s-c IIIB \\
\hline & Rogaland & VI 03802 & Water & Yes & No & 0 & S. diclina & S. diclina s-c IIIB \\
\hline & Rogaland & VI 03803 & Water & Yes & No & 1 & S. diclina & S. diclina s-c IIIA \\
\hline \multirow[t]{3}{*}{20} & N. Trøndelag & VI 03821 & Water & Yes & No & 0 & S. diclina & S. diclina s-c IIIB \\
\hline & N. Trøndelag & VI 03822 & Water & Yes & No & 2 & S. diclina & S. diclina s-c IIIB \\
\hline & N. Trøndelag & VI 03823 & Water & Yes & No & 0 & S. diclina & S. diclina s-c IIIB \\
\hline \multirow[t]{2}{*}{21} & N. Trøndelag & VI 03824 & Water & Yes & No & 0 & S. diclina & S. diclina s-c IIIB \\
\hline & N. Trøndelag & VI 03825 & Water & No & No & 42 & S. diclina & S. diclina s-c IIIB \\
\hline \multirow[t]{3}{*}{22} & Troms & VI 05299 & Water & Yes & No & 0 & S. diclina* ${ }^{*}$ & NA \\
\hline & Troms & VI 03826 & Water & Yes & No & 0 & S. diclina & S. diclina s-c IIIB \\
\hline & Troms & VI 03827 & Water & Yes & No & 0 & S. diclina & S. diclina s-c IIIB \\
\hline \multirow[t]{4}{*}{23} & Hordaland & VI 03828 & Water & Yes & No & 1 & S. diclina & S. diclina s-c IIIB \\
\hline & Hordaland & VI 03829 & Water & Yes & No & 0 & S. diclina & S. diclina s-c IIIB \\
\hline & Hordaland & VI 03830 & Water & Yes & No & 2 & S. diclina & S. diclina s-c IIIB \\
\hline & Hordaland & VI 05297 & Eggs & Yes & No & 4 & S. diclina* & NA \\
\hline \multirow[t]{5}{*}{24} & Møre og Romsdal & VI 05413 & Fry & No & Yes & 66 & S. parasitica & S. parasitica \\
\hline & Møre og Romsdal & VI 05414 & Fry & Yes & Yes & 59 & S. parasitica & S. parasitica \\
\hline & Møre og Romsdal & VI 05295 & Fry & No & Yes & 61 & S. parasitica* ${ }^{*}$ & NA \\
\hline & Møre og Romsdal & VI 05416 & Water & Yes & No & 4 & S. diclina & S. diclina s-c IIIA \\
\hline & Møre og Romsdal & VI 05417 & Water & Yes & No & 4 & S. diclina & S. diclina s-c IIIA \\
\hline \multirow[t]{5}{*}{25} & S. Trøndelag & VI 05418 & Eggs & Yes & No & 7 & Saprolegnia sp. & S. diclina s-c IIIA \\
\hline & S. Trøndelag & VI 05419 & Water & Yes & No & 3 & S. diclina & S. diclina s-c IIIA \\
\hline & S. Trøndelag & Vi 05420 & Water & Yes & No & 1 & S. diclina & S. diclina s-c IIIA \\
\hline & S. Trøndelag & VI 05421 & Water & No & No & 0 & S. diclina & S. diclina s-c IIIA \\
\hline & S. Trøndelag & VI 05415 & Water & No & Yes & 59 & S. parasitica & S. diclina s-c IIIA \\
\hline \multirow[t]{5}{*}{26} & Hordaland & VI 05425 & Water & Yes & No & 1 & S. ferax & S. ferax \\
\hline & Hordaland & VI 05426 & Water & Yes & No & 2 & S. ferax & S. ferax \\
\hline & Hordaland & VI 05427 & Eggs & Yes & No & 4 & S. ferax & S. ferax \\
\hline & Hordaland & VI 05435 & Eggs & Yes & No & 0 & S. diclina & S. diclina s-c IIIB \\
\hline & Hordaland & VI 05448 & Water & Yes & No & 0 & S. diclina & S. diclina s-c IIIB \\
\hline
\end{tabular}

(Applied Biosystems, Life Technologies) according to the manufacturer's instructions, and subsequently analysed on an ABI PRISM ${ }^{\circledR} 3100$ - Avant Genetic Analyzer (Applied Biosystems). Assembly and manual editing of the sequence chromatograms was conducted in BioEdit (Hall 1999).

All sequences generated in this study are available from the EMBL/GenBank sequence databases. The ITS sequences were compared to existing sequences in public sequence databases using NCBI nucleotide BLAST (Basic Local Alignment Search Tool: Altschul et al. 1997). Publicly available
ITS sequences representing a selection of relevant species within the family Saprolegniaceae including the closest matches obtained through the BLAST searches were aligned in BioEdit along with the sequences of this study using the ClustalW automatic alignment option followed by manual adjustments. Aphanomyces astaci (AM947024) was used as the outgroup. The alignment was analysed with MEGA v.5.01 (Tamura et al. 2011) using maximum parsimony phylogeny reconstruction with all sites included and close-neighbour-interchange on random trees as the search method. The phylogeny 
was tested with 1000 bootstrap replicates using the same settings. Corresponding analyses excluding gaps were also performed. Additionally, analyses were conducted in TNT version 1.1 (Goloboff et al. 2008) and PAUP* v4.0b10 (Swofford 2003) using maximum parsimony analyses with heuristic searches (1000 random addition sequences) and TBR branch swapping, saving 10 trees per replication. In the TNT analysis, gaps were included as an extra (5th) character, while in the PAUP analysis gaps were treated as missing. Standard bootstrap (Felsenstein 1985) and jackknife (Farris et al. 1996) procedures, the latter performed using $36 \%$ deletion, were conducted in TNT with 1000 replicates (traditional search) and with a cut-off value of $50 \%$. In PAUP, bootstrap analysis was performed with 1000 bootstrap replicates using a heuristic search algorithm and 1000 random additions of sequences per bootstrap replicate.

\section{RESULTS}

\section{Morphological characterization}

In total, 89 pure culture isolates obtained from 26 different hatcheries were characterized morphologically. Four different species were recognized based on morphological and physiological characteristics: Saprolegnia diclina, S. parasitica, S. hypogyna and $S$. ferax. Additionally, a group of 15 isolates that could not be assigned with confidence to a species was denoted as Saprolegnia sp. All isolates assigned to $S$. diclina were of the presumed saprophytic type according to the morphological characterization. $S$. diclina was the most prevalent species, comprising $70(79 \%)$ of the examined culture isolates (Table 2). Ten isolates $(11 \%)$ were determined to be $S$. parasitica, 2 isolates $(2 \%)$ were designated S. hypogyna, and 3 isolates $(3 \%)$ were assigned to the species S. erax.

Table 2. Characterized Saprolegnia isolates in relation to their source

\begin{tabular}{|lcccc|}
\hline Isolate & Water & Eggs & Tissue & Total \\
\hline S. diclina sub-clade IIIA & 10 & 1 & 0 & 11 \\
S. diclina sub-clade IIIB & 46 & 11 & 2 & 59 \\
S. parasitica & 2 & 2 & 6 & 10 \\
S. hypogyna & 2 & 0 & 0 & 2 \\
S. ferax & 2 & 1 & 0 & 3 \\
Scoliolegnia sp. & 4 & 0 & 0 & 4 \\
Total & 66 & 15 & 8 & 89 \\
\hline
\end{tabular}

\section{Molecular characterization}

The sequence alignment of ITS included 28 publicly available reference sequences of species within the family Saprolegniaceae (Saprolegnia, Leptolegnia, Scoliolegnia, Aphanomyces) and 73 sequences of putative Saprolegnia spp. generated in this study. The bootstrap consensus tree resulting from the Mega 5 parsimony analysis (Fig. 1) demonstrates that the vast majority $(79 \%)$ of the sequenced isolates grouped within clade III of the $S$. diclina complex following the clade annotations of Diéguez-Uribeondo et al. (2007). This clade was further split into 2 strongly supported sub-clades, hereafter referred to as S. diclina sub-clade IIIA and IIIB (Fig. 1). Only 9 of the isolates $(12 \%)$ grouped with well annotated reference sequences of $S$. diclina, such as SAP243 (AM228848) within sub-clade IIIA, while 49 of the isolates $(67 \%)$ grouped in the novel sub-clade IIIB with the previously published isolates VI04022 and SAP151 (AM947036 and AM228782, respectively). These are annotated Saprolegnia cf. ferax in GenBank, but both ITS sequence similarity and phylogenetic analysis support a closer affinity to $S$. diclina than to $S$. ferax. Seven isolates grouped with the $S$. parasitica sequences and 3 isolates grouped with Scoliolegnia asterophora (AB219398) in a $100 \%$ bootstrap supported clade, but constituted a unique genotype sharing $98 \%$ sequence identity to $S$. asterophora. The analyses conducted with MEGA, PAUP and TNT were largely congruent, with only minor differences in the statistical bootstrap support values for the different clades (data not shown). For a subset of isolates from each clade, sequences from the GH18 domains of chitinase genes generated according to Hochwimmer et al. (2009) supported the ITS-based species identification (data not shown).

\section{Isolated strains related to geography}

When extracting isolates from the 3 main geographical salmon producing regions, viz. western, central and northern Norway, species diversity was highest in western Norway, which also had the highest total number of isolates, and lowest in northern Norway, which had the lowest total number of isolates. The frequency of $S$. diclina sub-clade IIIB was high in all regions, but higher in central than in western Norway, albeit at a low significance level $(\mathrm{p}=$ $0.08 ; \mathrm{JMP}^{\circledR}$ Software). Species distributions within the geographical regions are summarized graphically in Fig. 2. 



Fig. 2. Regional overview of isolates, showing that Saprolegnia diclina sub-clade IIIB is the dominating taxon $(>50 \%)$ in all regions examined

\section{Isolated strains related to source}

A total of 66 isolates originated from water samples, 15 were isolated from eggs, and 8 were isolated from infected tissues of fry and broodfish. Isolates from tissue samples were dominated by $S$. parasitica (6 isolates), while $S$. diclina sub-clade IIIB accounted for the remaining 2 isolates. Isolates originating from eggs comprised $13 \mathrm{~S}$. diclina and 2 S. parasitica (see Table 2). The isolated species related to their source of isolation are listed in Table 2 .

\section{DISCUSSION}

The present study is the first extensive survey on the occurrence of Saprolegnia species in Norwegian salmon hatcheries. Only 4 different Saprolegnia spp. were isolated. The low diversity of Saprolegnia spp., with a clear dominance of $S$. diclina sub-clade IIIB in all geographical regions, was surprising given the number of hatcheries and their substantial geographical spread. Both Olàh \& Farkas (1978), Wood \& Willoughby (1986) and Maestres (1977) found greater numbers of species in single natural water locations. Also, Fregeneda-Grandes et al. (2007) identified 7 different species from 1 brown trout Salmo trutta hatchery in the province of Leòn, Spain. Possible explanations for the low species diversity recorded includes that the sampling was performed in the winter when minima in total spore load and species number have been reported previously (Maestres 1977, Langvad 1994). Nevertheless, if the species composition in hatchery water systems reflects the diversity in free water systems, it seems unlikely that 1 specific clade of Saprolegnia should be over-represented to the degree observed. We thus believe other explanations must be considered. Recently, Ali et al. (2013) showed that Saprolegnia spp. are able to form, live and propagate in biofilms, both experimentally and by analysing natural biofilms from fish tanks. Biofilms are believed to serve as a protective environment and provide nutrition under unfavorable conditions, and was proposed by Ali et al. (2013) as a possible explanation for recurring infections after chemical treatments. We speculate that certain competitive isolates may be able to establish and propagate in biofilm communities, and subsequently dominate spore numbers, if they are favoured by the special environmental conditions inside the plastic water pipes and indoor tanks. The relevance of this hypothesis is increasing with the rapid introduction of recirculating aquaculture systems, where spores presumably are accumulated in the system, resulting in high spore counts and potentially high infection pressures. However, these aspects are poorly explored and more indepth studies on the ecology of different Saprolegnia species, including biofilm formation, in aquaculture water systems could yield knowledge of vital importance for designing combat strategies and should be welcomed.

We demonstrate a clear dominance of isolates assigned to a sub-clade of $S$. diclina type III (Diéguez-Uribeondo et al. 2007), both in hatchery water and infected salmon eggs. More specifically, the well resolved and $99 \%$ bootstrap-supported S. diclina 
sub-clade IIIB dominated. This sub-clade has not been recognized in previous studies, and the only publicly available representatives of the group are erroneously annotated Saprolegnia cf. ferax (VI04022/ AM947036 and SAP151/AM228782). Our study clearly demonstrates, both in terms of morphology and phylogeny, that these isolates are distant from $S$. ferax, and rather are assigned to the IIIB sub-clade of $S$. diclina. The ITS sequences of the 2 sub-clades of the $S$. diclina complex are separated by 10 consistent substitutions and 1 insertion/deletion over 660 base pairs, corresponding to $98 \%$ sequence identity. Whether this reflects 2 independent species or simply intraspecific ITS variation within the $S$. diclina type III awaits further molecular analyses of a wider range of genetic markers suitable for oomycete species delimitation. Parsimony analyses of the independent dataset of chitinase genes were largely congruent with the ITS phylogeny and supported 2 different genotypes of the $S$. diclina sub-clade IIIA and IIIB isolates. However, these data were not included due to presently unresolved problems with insufficient sequence accuracy that may relate to the simultaneous amplification and sequencing of the 3 slightly different homologues of chitinase genes CHI1, CHI2 and CHI3 (see Hochwimmer et al. 2009).

The congruence between morphological and molecular identification was generally good, even though a considerable number of strains could not be assigned with certainty to species level with the morphological criteria available. Especially the isolates identified to $S$. diclina displayed heterogeneous morphology in sexual structures, making confident identification difficult. However, morphological and physiological identification was satisfactory to distinguish $S$. parasitica from the other species. Of note, no presumed pathogenic isolates of $S$. diclina type I (DiéguezUribeondo et al. 2007) were identified. Also, the molecular analysis revealed the erroneous identification to the genus Saprolegnia of 4 isolates of Scoliolegnia sp. These expressed what seemed to be a saprolegnoid zoospore release, but could not be assigned to species level from sexual structure morphology.

Finally, since we aimed to obtain a basic overview over a broad geographic range, only a limited number of isolates per hatchery were selected for characterization. It is therefore likely that Saprolegnia species with low prevalence have escaped our detection.

None of the hatcheries experienced outbreaks of saprolegniosis in the sampling period of this project, which may relate to higher egg quality and increased knowledge on precautionary actions to reduce the Saprolegnia problem (i.e. immediate removal of in- fected eggs as recommended by Thoen et al. 2010). Consequently, we received only a limited number of egg and tissue samples. The observation that $S$. diclina sub-clade IIIB isolates also dominated infected eggs $(73 \%)$ seems natural considering the high overall prevalence in the hatchery water systems. It is also in concordance with Thoen et al. (2011), who demonstrated through a challenge experiment that a presumed saprotrophic isolate was the single most pathogenic isolate to salmon eggs. Even though $S$. diclina is often believed to be a saprophytic species, our results may suggest that this species is responsible for a considerable portion of the eggs lost in saprolegniosis in Norway. These observations also correlate well with Fregeneda-Grandes et al. (2007), who reported an over-representation of $S$. diclina among isolates originating from brown trout eggs. In our study, $S$. diclina sub-clade IIIB was somewhat surprisingly isolated from 2 broodfish gill samples. This was likely due to the compromised immune status of the sexually mature fish. On the other hand, presumed pathogenic $S$. parasitica isolates were only found in 2 water samples, but were more frequently isolated from infected salmon tissues than other species. This may reflect the pathogenic potential of this species to post-hatching stages even when present at low prevalence, and corroborates previous findings (Hatai et al. 1990, Hatai \& Hoshiai 1992, FregenedaGrandes et al. 2007).

In conclusion, our study revealed a limited diversity of Saprolegnia species present in Norwegian salmon hatcheries, dominated by saprobiotic $S$. diclina strains which are possibly adapted to the special environmental conditions found in the water systems investigated here. This aspect could be further explored by comparing water samples from the water source (prior to entering the tube system) with hatchery water. Molecular tools were of decisive importance in species determination for a number of isolates that could not be determined by morphology alone, and allowed further delimitation of $S$. diclina isolates into 2 strongly supported sub-clades. The presumed saprotrophic isolates of $S$. diclina type IIIB frequently isolated from salmon eggs may be causative agents in egg saprolegniosis. Future studies should explore this lineage in further detail, with regard to pathogenic potential, niche preferences and species delimitation.

Acknowledgements. The experiments were performed with funding from the Norwegian Research Council (project number 159755/S-40) and the National Veterinary Institute, Norway. We also sincerely thank AquaGen AS for valuable help with sampling. 


\section{LITERATURE CITED}

Ali SE, Thoen E, Evensen Ø, Skaar I (2013) Development and reproduction of Saprolegnia species in biofilms. Vet Microbiol 163:133-141

Altschul SF, Madden TL, Schäffer AA, Zhang J, Zhang Z, Miller W, Lipman DJ (1997) Gapped BLAST and PSIBLAST: a new generation of protein database search programs. Nucleic Acids Res 25:3389-402

Beakes GW, Wood SE, Burr AW (1994) Features which characterize Saprolegnia isolates from salmon fish lesions - a review. In: Mueller GJ (ed) Salmon saprolegniasis. Bonneville Power Administration, Div. Fish and Wildlife, Portland, OR, p 52-66

Diéguez-Uribeondo J, Fregeneda-Grandes JM, Cerenius L, Pèrez-Iniesta E and others (2007) Re-evaluation of the enigmatic species complex Saprolegnia diclina-Saprolegnia parasitica based on morphological, physiological and molecular data. Fungal Genet Biol 44:585-601

Farris JS, Albert VA, Källersjö M, Lipscomb D, Kluge AG (1996) Parsimony jackknifing outperforms neighborjoining. Cladistics 12:99-124

Felsenstein J (1985) Phylogenies and the comparative method. Am Nat 125:1-15

Fregeneda-Grandes JM, Rodriguez-Cadenas F, AllerGancedo JM (2007) Fungi isolated from cultured eggs, alevins and broodfish of brown trout in a hatchery affected by saprolegniosis. J Fish Biol 71:510-518

Gardes M, Bruns TD (1993) ITS primers with enhanced specificity for basidiomycetes - application to the identification of mycorrhizae and rusts. Mol Ecol 2:113-118

Goloboff PA, Farris JS, Nixon KC (2008) TNT, a free program for phylogenetic analysis. Cladistics 24:774-786

Hall TA (1999) BioEdit: a user-friendly biological sequence alignment editor and analysis program for Windows 95/98/NT. Nucleic Acids Symp Ser 41:95-98

> Hatai K, Hoshiai G (1992) Mass mortality in cultured coho salmon (Oncorhynchus kisutch) due to Sparolegnia parasitica Coker. J Wildl Dis 28:532-536

> Hatai K, Willoughby LG, Beakes GW (1990) Some characteristics from Saprolegnia obtained from fish hatcheries in Japan. Mycol Res 94:182-190

Hochwimmer G, Tober R, Bibars-Reiter R, Licek E, Steinborn R (2009) Identification of two GH18 chitinase family genes and their use as targets for detection of the crayfish-plague oomycete Aphanomyces astaci. BMC Microbiol 9:184

Hughes GC (1994) Saprolegniasis: then and now: a retrospective. In: Mueller GJ (ed) Salmon saprolegniasis. Bonneville Power Administration, Division of Fish and Wildlife, Portland, OR, p 3-32

Hussein MMA, Hatai K (2002) Pathogenicity of Saprolegnia species associated with outbreaks of salmonid saprolegniosis in Japan. Fish Sci 68:1067-1072

Hussein MMA, Hatai K, Nomura T (2001) Saprolegniosis in salmonids and their eggs in Japan. J Wildl Dis 37: 204-207

Editorial responsibility: David Bruno,

Aberdeen, UK
Kitancharoen N, Yamamoto A, Hatai K (1997) Fungicidal effects of hydrogen peroxide on fungal infection of rainbow trout eggs. Mycoscience 38:375-378

Langvad F (1994) Saprolegnia in Norwegian fish farming. In: Mueller GJ (ed) Salmon saprolegniasis. Bonneville Power Administration, Division of Fish and Wildlife, Portland, OR, p 188-201

Maestres LE (1977) A quantitative ecological study of aquatic fungi from Broadcove river with emphasis on representatives of the genus Saprolegnia. MSc thesis. Memorial University, St. John's, Newfoundland

Olàh J, Farkas J (1978) Effect of temperature, pH, antibiotics, formalin and malachite green on the growth and survival of Saprolegnia and Achlya parasitic to fishes. Aquaculture 13:273-288

Seymour RL (1970) The genus Saprolegnia. Verlag von J. Cramer, Lehre

> Stueland S, Hatai K, Skaar I (2005) Morphological and physiological characteristics of Saprolegnia spp. strains pathogenic to Atlantic salmon, Salmo salar L. J Fish Dis 28: 445-453

Swofford DL (2003) PAUP*. Phylogenetic Analysis Using Parsimony (*and Other Methods). Version 4. Sinauer Associates, Sunderland, MA

Tamura K, Peterson D, Peterson N, Stecher G, Nei M, Kumar S (2011) MEGA5: molecular evolutionary genetics analysis using maximum likelihood, evolutionary distance, and maximum parsimony methods. Mol Biol Evol 28: 2731-2739

Thoen E, Evensen Ø, Skaar I (2010) Microwell enumeration of viable Saprolegniaceae in water samples. Mycologia 102:478-485

> Thoen E, Evensen Ø, Skaar I (2011) Pathogenicity of Saprolegnia spp. to Atlantic salmon, Salmo salar L., eggs. J Fish Dis 34:601-608

van West P (2006) Saprolegnia parasitica, an oomycete pathogen with a fishy appetite: new challenges for an old problem. Mycologist 20:99-104

Vrålstad T, Knutsen AK, Tengs T, Holst-Jensen A (2009) A quantitative TaqMan MGB real-time polymerase chain reaction based assay for detection of the causative agent of crayfish plague Aphanomyces astaci. Vet Microbiol 137:146-155

White TJ, Bruns T, Lee S, Taylor J (1990) Amplification and direct sequencing of fungal ribosomal RNA genes for phylogenetics. In: Innis MA, Gelfand DH, Sninsky JJ, White TJ (eds) PCR protocols: a guide to methods and applications. Academic Press, San Diego, CA, p 315-322

Willoughby LG (1985) Rapid preliminary screening of Saprolegnia on fish. J Fish Dis 8:473-476

Wood SE, Willoughby LG (1986) Ecological observations on the fungal colonization of fish by Saprolegniaceae in Windermere. J Appl Ecol 23:737-749

Yuasa K, Kitancharoen N, Hatai K (1997) Simple method to distinguish between Saprolegnia parasitica and $S$. diclina isolated from fishes with saprolegniasis. Fish Pathol 32:75-176

Submitted: September 30, 2014; Accepted: March 9, 2015 Proofs received from author(s): May 26, 2015 